\title{
Analysis of Phthalate Presence in Agricultural Soils in the Czech Republic
}

\author{
Radka Daňková1, Alžbeta Jarošová ${ }^{1}$, Šárka Poláková ${ }^{2}$ \\ ${ }^{1}$ Mendel University in Brno, \\ Zemědělská 1, 61300 Brno, Czech Republic \\ ${ }^{2}$ Central Institute for Supervising and Testing in Agriculture, \\ Brno, Czech Republic
}

Received: 10 October 2015

Accepted: 21 October 2015

\begin{abstract}
Our study monitored two phthalic acid esters in agricultural soils in the Czech Republic: di2ethylhexyl phthalate (DEHP) and dibutyl phthalate (DBP). The concentration levels were determined using high-performance liquid chromatography with UV detection. The samples were extracted using an acetone-hexane (1:1) mixture. Phthalate content monitoring was performed in 12 administrative regions of the Czech Republic. Soil was sampled from the upper soil horizon along the polyline, with samples taken from the following cultures: arable land, permanent grassland, a hop field, and unfarmed land. The phthalic acid ester concentrations found ranged from 0.01 to $2.48 \mathrm{mg}$ per $\mathrm{kg}$ of DM wt for dibutyl phthalate and from 0.05 to $1.43 \mathrm{mg}$ per $\mathrm{kg}$ of DM wt for di2ethylhexyl phthalate. The total concentration of both phthalates ranged from 0.21 to $3.47 \mathrm{mg}$ per $\mathrm{kg}$ of DM wt.
\end{abstract}

Keywords: agricultural soil, dibutyl phthalate, di2ethylhexyl phthalate

\section{Introduction}

With their favourable properties, phthalic acid esters (PAE) find a wide range of applications in numerous fields of industrial production for their high stability and low volatility [1]. As a result, they have become ubiquitous in the environment. Despite efforts to reduce their production and replace the compounds with substances less harmful to human health, the substances can still be found in a number of common everyday products such as paints, varnishes, sealants, adhesives, floor coverings, coats, household equipment, clothing, cosmetics, and healthcare products, and to a limited extent in food packaging materials [2-4].

*e-mail: radka.dankova@mendelu.cz
While potential routes of human exposure consist of air, skin contact, and water, food is considered the main source of exposure to phthalates in humans. Foods can be contaminated with phthalates from the very beginning, through contamination of input materials, during processing, and up to the contamination of finished products by packaging materials [5].

Since agricultural land is a factor for the quality and health safety for foods of both plant and animal origin, knowing the contents of contaminants in soils is of utmost importance. Elevated concentrations in agricultural soils tend to be the result of increased human activity, particularly in areas with intense industrial activities where there is chiefly atmospheric deposition of these substances, via both wet and dry routes. Elevated levels in such areas tend to be detected for other contaminants 
as well, such as PCBs, PAHs, and heavy metals. Other reasons for the elevated concentration can often include an intense agricultural activity $[4,6,7]$.

Thus, plants can easily receive the substances while absorbing nutrients, which particularly occurs via the root system and green aerial parts. This may lead to the food chain becoming contaminated [6]. Plant species specificity is an important factor for the uptake of these substances by the plant [8].

The lipophilic nature of phthalates can also cause phthalates to accumulate in animal tissues (muscle, fat) from feedstuffs and the environment. Phthalates can also pass from the digestive tract into milk [9]. The milk of sheep grazing on pastures fertilised with sludge originating from water treatment plants and containing a certain quantity of phthalates was found to contain twice the concentration of phthalates compared with the surrounding environment, suggesting that the phthalates accumulate in milk.

The rate of accumulation of phthalic acid esters depends on their solubility, octanol/water partition coefficients, and the degradation of the esters via chemical or biological routes. The degradation and the corresponding half-life of PAE correlate with the length of the alkyl chain and PAE octanol/water partition coefficients [1].

Phthalates present substances potentially hazardous for human health, particularly because of their negative effects on the human reproductive system; a carcinogenic and teratogenic nature of phthalates was also demonstrated in mice, rats, or chickens [10-14].

Since dibutyl phthalate (DBP) and di2ethylhexyl phthalate (DEHP) are the most widespread phthalic acid esters (PAE) in soil and the environment, the compounds became the target of this study - the first of its type performed in the Czech Republic.

\section{Materials and Methods}

\section{Sampling}

Samples of agricultural soil were taken in cooperation with the Central Institute for Supervising and Testing in Agriculture in Brno. The sites were chosen from within the scope of the annual basal monitoring of soils performed by the Central Institute for Supervising and Testing in Agriculture. The placement of the sites allows the determination of any chosen parameter so that the results could characterize the entire studied area, after proper statistical evaluation of the results is performed. The approach focused on an areally uneven network with proportional representation of the main soil types and individual agricultural cultures grown in the area. The samples included soils from 12 out of the 14 administrative regions of the Czech Republic: South Bohemian, Central Bohemian, Plzeň, Karlovy Vary, Ústí nad Labem, Liberec, Pardubice, Vysočina, Zlín, South Moravian, Olomouc, and Moravian-Silesian.

Soil samples were collected from upper horizons, the horizon depth varying per culture. The following horizon

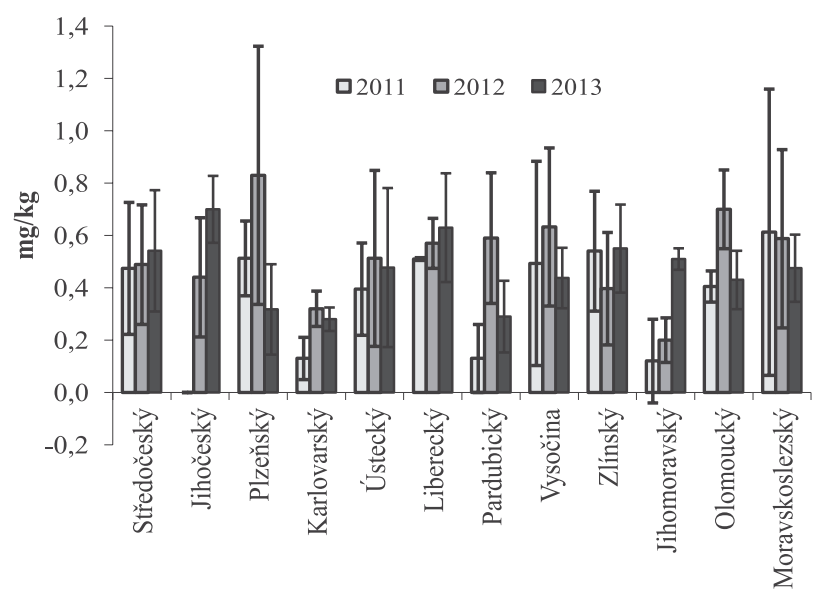

Fig. 1. Comparison of dibutyl phthalate concentrations in 2011, 2012, and 2013.

samples were taken: arable land (AL) $0-25 \mathrm{~cm}$, permanent grassland (PG) $0-10 \mathrm{~cm}$ with the removal of the top layer of the turf, hop-field (HF) $10-40 \mathrm{~cm}$, with about $0.5 \mathrm{~kg}$ of soil per horizon sampled. The quantity was manually homogenised in the field, while removing the coarser skeleton. Packed and labelled, the samples were transported in cooling boxes and then stored in a freezer at $-18^{\circ} \mathrm{C}$ until transferred to the laboratory.

\section{Chemicals and Equipment}

Lyophiliser Alpha 1-2 LD Plus (Christ, Germany) was used for freeze-drying the samples. Sample extraction was carried out using a PS 10000 ultrasonic device (Notus-Powersonic, Slovakia), with an acetone-hexane p.a. mixture used for extraction (Penta, Czech Republic). The extracts were evaporated using an RV 05-ST rotary vacuum evaporator (JK IKA-Werke, Germany) and then dried with technical nitrogen 4.0 (SIAD, Czech Republic). Purification of the sample was done by concentrated sulphuric acid p.a. (Penta, Czech Republic) with use of a 3005 shaker (GFL, Germany) and a Universal 32R centrifuge (Het-

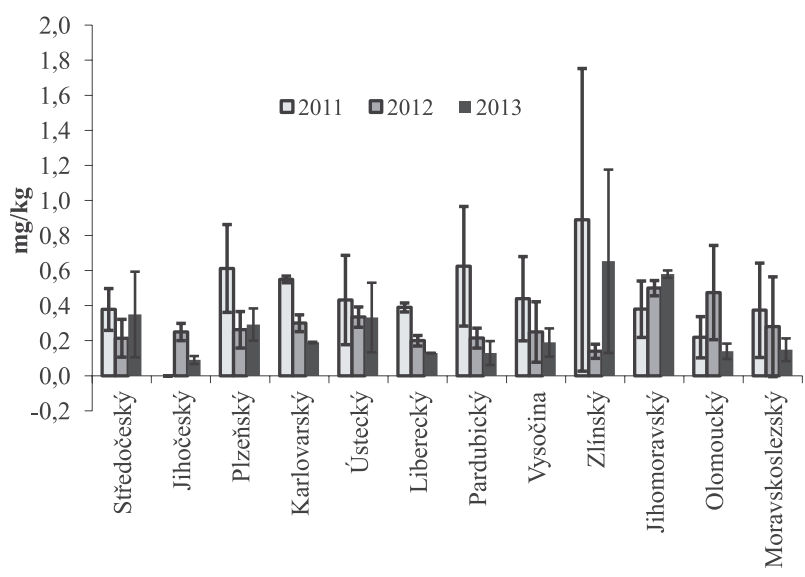

Fig. 2. Comparison of di 2 ethylhexyl phthalate concentrations in 2011, 2012, and 2013. 
tich, Germany). The analysis was carried out using an HP 1100 liquid chromatograph (Agilent Technologies, USA), and a Zorbax Eclipse XDB-C8 column, 150 x $4.6 \mathrm{~mm}$, $5 \mu \mathrm{m}$ (Agilent Technologies, USA). DEHP (Fluka Analytical, Germany) and DBP (Supelco Analytical, USA) standards were used for this study. Gradient-grade acetonitrile (JT Baker, the Netherlands) was used as the mobile phase.

\section{Sample Pre-Treatment}

The frozen samples were thawed and about $10 \mathrm{~g}$ of soil were removed from each. Subsequently, the $10 \mathrm{~g}$ of soil were refrozen and then freeze-dried, followed by extraction by the acetone-hexane 1:1 mixture using the ultrasonic device; this was repeated three times within five minutes. The combined extracts were filtered and concentrated using a vacuum rotary evaporator and completely dried with nitrogen. The extracts were then transferred into vials using hexane. This was followed by a purification with sulphuric acid, which was first concentrated and then hydrated [15]. The purified samples were further dried with nitrogen until dry and acetonitrile was then added with a standard addition of DBP and DEHP $(39 \mu \mathrm{g} / \mathrm{ml})$ to a volume of $1 \mathrm{ml}$. Analysis of all samples was performed in duplicate.

\section{HPLC Analysis}

Phthalate analysis was performed using HPLC with UV detection at a wavelength of $224 \mathrm{~nm}$. All samples were injected twice. Sample injection volume was $10 \mu \mathrm{l}$. The column used was Zorbax Eclipse C8, with acetonitrile used as the mobile phase. The results were evaluated by the calibration curve using Agilent ChemStation software for LC and LC/MS systems. The calibration curve was created in the concentration range of $1-112 \mu \mathrm{g} / \mathrm{ml}$ for DBP and DEHP, with the correlation coefficient being 0.9999 for DBP and 0.9999 for DEHP.

The yield of the method achieved values of $91 \pm 9 \%$ for DBP and $93 \pm 12 \%$ for DEHP at a concentration level of $3.6 \mu \mathrm{g} / \mathrm{g}$ (DBP and DEHP).

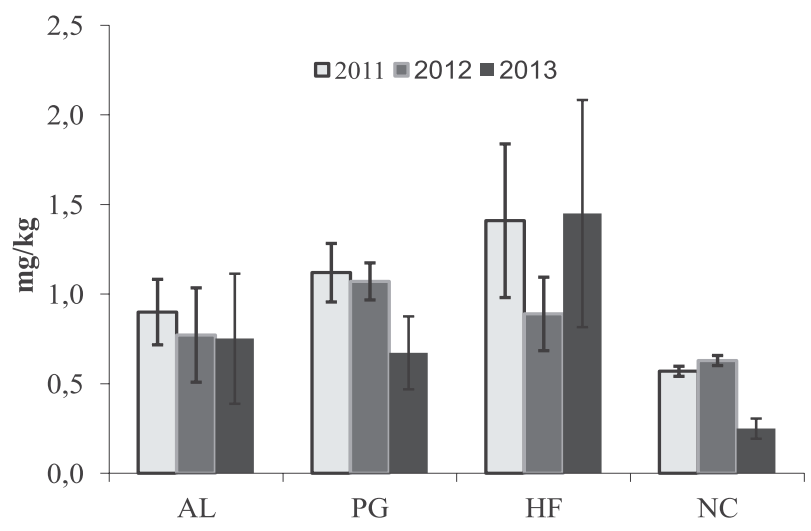

Fig. 3. Comparison of DBP and DEHP concentrations per culture. $\mathrm{AL}$ - arable land, $\mathrm{PG}$ - permanent grassland, HF - hop field, $\mathrm{NC}-$ not cultivated

\section{Results and Discussion}

The concentrations of phthalic acid esters identified in this study are in the order of hundredths of mg per $\mathrm{kg}$ DM wt. As is evident from Figs 1 and 2 provided below, the values are comparable with other studies carried out in Europe $[4,16,17]$. When compared with studies carried out in Asia, the results of these studies range in the order of tenths of mg per $\mathrm{kg}$ DM wt $[6,7,18,19]$.

The elevated content of phthalates in the soil is hazardous due to possible transfer to the plant via the root system, which naturally depends on the type of plant; bioconcentration factors are, however, relatively low [8]. There is also a particular risk of phthalates accumulating as lipophilic substances in animal fats [9, 20]. Fierens et al. [21] examined the effect of the environment and milking equipment on the phthalate content in cow's milk from two farms. The concentration of phthalates in the soil was the basis for the computing values of phthalate uptake from soil.

The content of phthalic acid esters in soils varied based on the soil cultivation method. The total content of dibutyl phthalate and di2ethylhexyl phthalate based on the culture is shown in Fig. 3.

When comparing the concentration levels established in the present study with the values set by the Ministry of the Environment of the Czech Republic and stated in its guideline stemming from the regional screening levels published by the United States Environmental Protection Agency, none of these values were exceeded in this study [22].

Van Wezel et al. [23] determined in their study the values of environmental risk for DEHP and DBP. For soil and sediments containing $10 \%$ organic matter, it is about $0.7 \mathrm{mg}$ per $\mathrm{kg}$ of native weight for DBP and $1.0 \mathrm{mg}$ per $\mathrm{kg}$ of native weight for DEHP.

\section{Conclusion}

Monitoring phthalic acid esters in agricultural soils is very important not only in terms of environmental safety, but generally also in terms of safety of the food chain - thus also the protection of human health. The concentration levels described in this study were identified by means of high-performance liquid chromatography with UV detection. The observed levels lie far below the limits recommended by the Ministry of Environment of the Czech Republic. In 2013, there was no significant increase or decrease in the concentration of each of the phthalic acid esters compared to 2012 and 2011.

\section{Acknowledgements}

Our study was supported by the Internal Grant Agency of AF MENDELU, project ID: IP12/2012. 


\section{References}

1. JIANLONG W., XUAN Z., WEIZHONG W. Biodegradation of phthalic acid esters (PAEs) in soil bioaugmented with acclimated activated sludge. Process Biochemistry 39, 1837, 2004.

2. STAPLES C.A., PETERSON D.R., PARKERTON T.F., ADAMS W.J. The environmental fate of phthalate esters: A literature review. Chemosphere 35, 667, 1997.

3. OTTON S.V., SURA S., BLAIR J., IKONOMOU M.G., GOBAS F.A.P. C. Biodegradation of mono-alkyl phthalate esters in natural sediments. Chemosphere 71, 2011, 2008.

4. VIKELSOE J., THOMSEN M., CARLSEN L. Phthalates and nonylphenols in profiles of differently dressed soils. Science of the Total Environment 296, 105, 2002.

5. NANNI N., FISELIER K., GROB K., DI PASQUALE M., FABRIZI L., AURELI P., CONI E. Contamination of vegetable oils marketed in Italy by phthalic acid esters. Food Control 22, 209, 2011

6. ZENG F., CUI K., XIE Z., LUO D., CHEN L., LIN Y., LIU M., SUN G. Distribution of phthalate esters in urban soils of subtropical city, Guangzhou, China. Journal of Hazardous Materials 164, 1171, 2009.

7. CAI Q.Y., MO C.H., WU Q.T., ZENG Q.Y. Accumulation of phthalic acid esters in water spinach (Ipomoea aquatica) and in paddy soil. Bulletin of Environmental Contamination and Toxicology 77, 411, 2006.

8. DUECK T.A., VAN DIJK C.J., DAVID F., SCHOLZ N., VANWALLEGHEM F. Chronic effects of vapour phase dinbutyl phthalate (DBP) on six plant species. Chemosphere 53, 911, 2003.

9. RHIND S.M., KYLE C.E., MACKIE C., TELFER G. Effects of exposure of ewes to sewage sludge-treated pasture on phthalate and alkyl phenol concentrations in their milk. Science of the Total Environment 383, 70, 2007.

10. ABDUL-GHANI S., YANAI J., ABDUL-GHANI R., PINKAS A., ABDEEN Z. The teratogenicity and behavioral teratogenicity of di(2ethylhexyl) phthalate (DEHP) and dibutyl phthalate (DBP) in a chick model. Neurotoxicology and Teratology 34, 56, 2012.

11. LI N., LIU T., ZHOU L., HE J., YE L. Di-(2-ethylhexyl) phthalate reduces progesterone levels and induces apoptosis of ovarian granulosa cell in adult female ICR mice. Environ. Toxicol. Pharmacol. 34, 869, 2012.

12. MTIBE A., MSAGATI T. A.M., MISHRA A.K., MAMBA B.B. Determination of phthalate ester plasticizers in the aquatic environment using hollow fibre supported liquid membranes. Physics and Chemistry of the Earth 50-52, 239, 2012.

13. LI M., QIU L., ZHANG Y., HUA Y., TU S., HE Y., WEN S., WANG G Q., WEI G. Dose-related effect by maternal exposure to di-(2-ethylhexyl) phthalate plasticizer on inducing hypospadiac male rats. Environmental Toxicology and Pharmacology, 35, 55, 2013.

14. MANKIDY R., WISEMAN S., MA H., GIESY J. P. Biological impact of phthalates. Toxicology Letters 217, 50, 2013.

15. THURÉN A., SÖDERGREN A. Clean-up with sulphuric acid prior to the gas chromatographic determination of phthalate esters. Int.J. Envoron. Anal. Chem. 28, 309, 1987.

16. GIBSON R., WANG M.-J., PADGETT E., BECK A.J. Analysis of 4-nonylphenols, phthalates, and polychlorinated biphenyls in soils and biosolids. Chemosphere 61, 1336, 2005.

17. ZORNÍKOVÁ G., JAROŠOVÁA., HŘIVNAL. Distribution of phthalic acid esters in agricultural plants and soils. Acta Universitatis Agriculturae et Silviculturae Mendelianae Brunensis 59, 233, 2011.

18. KONG S., JI Y., LIU L., CHEN L., ZHAO X., WANG J., BAI Z., SUN Z. Diversities of phthalate esters in suburban agricultural soils and wasteland soil appeared with urbanization in China. Environmental Pollution 170, 161, 2012.

19. XU G., LI F., WANG Q. Occurence and degradation characteristics of dibutyl phthalate (DBP) and di-(2ethylhexyl)phthalate (DEHP) in typical agricultural soils of China. Science of the Total Environment 393, 333, 2008.

20. FIERENS T., VAN HOLDERBEKE M., WILLEMS H., DE HENAUW S., SIOEN I. Transfer of eight phthalates through the milk chain - A case study. Environment International 51, $1,2013$.

21. FIERENS T., VAN HOLDERBEKE M., WILLEMS H., DE HENAUW S., SIOEN I. Phthalates in Belgian cow's milk and the role of feed and other contamination pathways at farm level. Food and Chemical Toxicology 50, 2945, 2012.

22. Metodický pokyn MŽP Indikátory znečištění [date cited: 13 September 2013] Available from: <http://www.mzp.cz/cz/ metodiky_ekologicke zateze>

23. VAN WEZEL A. P., VAN VLAARDINGEN P., POSTHUMUS R., CROMMENTUIJN G. H., SIJM D. T. Environmental risk limits for two phthalates, with special emphasis on endocrine disruptive properties. Ecotoxicology and Environmental Safety 46, 305, 2007. 